\title{
Incidence of Low Back Pain After Lumbar Discectomy for Herniated Disc and Its Effect on Patient-reported Outcomes
}

\author{
Scott L. Parker MD, Stephen K. Mendenhall BS, Saniya S. Godil MD, \\ Priya Sivasubramanian BS, Kevin Cahill MD, MPH, \\ John Ziewacz MD, MPH, Matthew J. McGirt MD
}

Published online: 19 February 2015

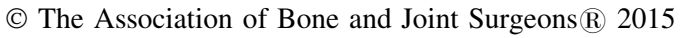

\begin{abstract}
Background Long-term postdiscectomy degenerative disc disease and low back pain is a well-recognized disorder; however, its patient-centered characterization and quantification are lacking.

Questions/purposes We performed a systematic literature review and prospective longitudinal study to determine the frequency of recurrent back pain after discectomy and quantify its effect on patient-reported outcomes (PROs).

Methods A MEDLINE search was performed to identify studies reporting on the frequency of recurrent back pain, same-level recurrent disc herniation, and reoperation after primary lumbar discectomy. After excluding studies that did not report the percentage of patients with persistent
\end{abstract}

\footnotetext{
Each author certifies that he or she, or a member of his or her immediate family, has no funding or commercial associations (eg, consultancies, stock ownership, equity interest, patent/licensing arrangements, etc) that might pose a conflict of interest in connection with the submitted article.

All ICMJE Conflict of Interest Forms for authors and Clinical Orthopaedics and Related Research ${ }^{\circledR}$ editors and board members are on file with the publication and can be viewed on request.

This work was performed at Vanderbilt University Medical Center, Nashville, TN, USA.
}

S. L. Parker, S. K. Mendenhall, S. S. Godil, P. Sivasubramanian Department of Neurosurgery, Vanderbilt University Medical Center, Nashville, TN, USA

K. Cahill, J. Ziewacz, M. J. McGirt ( $₫)$

Carolina Neurosurgery \& Spine Associates, 225 Baldwin

Avenue, Charlotte, NC 28204, USA

e-mail: matthewmcgirt@gmail.com back or leg pain more than 6 months after discectomy or did not report the rate of same level recurrent herniation, 90 studies, which in aggregate had evaluated 21,180 patients, were included in the systematic review portion of this study. For the longitudinal study, all patients undergoing primary lumbar discectomy between October 2010 and March 2013 were enrolled into our prospective spine registry. One hundred fifteen patients were more than 12 months out from surgery, 103 (90\%) of whom were available for 1-year outcomes assessment. PROs were prospectively assessed at baseline, 3 months, 1 year, and 2 years. The threshold of deterioration used to classify recurrent back pain was the minimum clinically important difference in back pain (Numeric Rating Scale Back Pain [NRS-BP]) or Disability (Oswestry Disability Index [ODI]), which were 2.5 of 10 points and 20 of 100 points, respectively.

Results Systematic Review The proportion of patients reporting short-term (6-24 months) and long-term (> 24 months) recurrent back pain ranged from 3\% to $34 \%$ and $5 \%$ to $36 \%$, respectively. The 2 -year incidence of recurrent disc herniation ranged from $0 \%$ to $23 \%$ and the frequency of reoperation ranged from $0 \%$ to $13 \%$.

Prospective Study At 1-year and 2-year followup, 22\% and $26 \%$ patients reported worsening of low back pain (NRS: $5.3 \pm 2.5$ versus $2.7 \pm 2.8, \mathrm{p}<0.001$ ) or disability (ODI\%: $32 \pm 18$ versus $21 \pm 18, \mathrm{p}<0.001$ ) compared with 3 months.

Conclusions In a systematic literature review and prospective outcomes study, the frequency of same-level disc herniation requiring reoperation was $6 \%$. Two-year recurrent low back pain may occur in $15 \%$ to $25 \%$ of patients depending on the level of recurrent pain considered clinically important, and this leads to worse PROs at 1 and 2 years postoperatively. 


\section{Introduction}

The most common procedure performed in the United States for patients experiencing back and leg pain is lumbar discectomy [5, 10]. In 2003, 2.1 per 1000 Medicare enrollees received a lumbar discectomy/laminectomy [92]. Although the procedure has been performed for decades, the reported proportion of postsurgical degenerative disc disease and recurrent back and leg pain in the literature has been highly variable, ranging from as low as $3 \%$ to as high as $43 \%$ [42, 75].

A common challenge for spine surgeons after lumbar discectomy is reherniation at the same level. There is a wide variation of reported reherniation rates in the literature and it is unclear how many patients with reherniation undergo reoperation such as revision discectomy or instrumented fusion. There is great interest in the topic of reherniation after discectomy because it is associated with high cost and poor outcome (recurrent back pain, recurrent disc herniation, or reoperation) [65].

Surgeons have attempted more aggressive discectomies to try to reduce the incidence of reherniation, but this approach has been associated with greater postoperative degeneration and back pain [57]. Sequestrectomies of disc fragments have also been adopted to minimize disc removal and subsequent degenerative back pain but have been associated with greater reherniation [57]. Long-term postdiscectomy degeneration and back pain remains a recognized pathology. However, its patient-centered characterization and quantification are lacking.

The aims of this article are twofold. First, through a systematic literature review, we aimed to determine (1) the proportion of patients with short-term (6 months to 2 years postoperatively) and long-term ( $>2$ years postoperatively) postdiscectomy recurrent back pain; and (2) the frequency of same-level recurrent disc herniation and reoperation for first-time single-level lumbar discectomy. Second, through the use of our prospective longitudinal spinal outcomes registry, we sought to determine the (1) proportion of patients with recurrent degenerative back pain; and (2) quantify its effect on patients' pain, disability, and quality of life.

\section{Materials and Methods}

\section{Literature Review}

We performed a literature review to identify all published articles that reported outcomes after discectomy for primary lumbar disc herniation. Because much of the current techniques that are used today were popularized in the late 1970s and early 1980s by Williams and Spengler, we limited our search to studies published after the introduction of their techniques (1980 to the present) [81, 96].

To answer the stated questions, search terms were identified and combined with appropriate Boolean connectors, and a search was carried out for English language publications on MEDLINE (PubMed). The search sequence submitted was the following: ("diskectomy" $[\mathrm{MeSH}] \mathrm{OR}$ discectomy[title] OR diskectomy[title]) AND ("lumbosacral region" [MeSH Terms] OR lumbar[Title] OR "lumbar vertebrae"[MeSH terms]) AND ("Treatment Outcome"[MeSH] OR "Outcome Assessment (Health Care)" [MeSH] OR (outcome[All Fields] OR surgical outcomes[All Fields]). Limits were English language and publication date between 1980 and 2013.

All titles that resulted from these search criteria were reviewed. Case reports, technical notes, and animal or laboratory studies were not included in the study. Abstracts were then reviewed for all remaining studies. Abstracts on discectomy cohorts that included fusion procedures, patients undergoing revision discectomy, pediatric or elderly patients (age $>70$ years), or other concurrent spinal pathologies were excluded. The remaining manuscripts were reviewed in their entirety. Only studies that assessed the incidence of recurrent or persistent symptoms more than 6 months after surgery or described the incidence of recurrent herniation were included for analysis.

For this systematic review, the primary endpoint assessed from each study was the persistent or recurrent back and leg pain that was reported to be clinically relevant to the patient or treating physician. However, this endpoint was not reported in a standardized fashion throughout the included studies. The majority of the studies reported the proportion of patients with persistent back and leg pain as fair to poor or moderate to poor outcome per the scales of Macnab [51], Prolo et al. [69], and Stauffer and Coventry [83]. The remaining studies plainly stated the incidence of persistent back or leg pain at the time of last patient followup evaluation. Despite the variation in reporting outcomes measures, each scale used persistent symptomatology to stratify outcome scores, making the categorical deduction of our endpoint possible. The incidence of recurrent or persistent back pain or leg pain, same-level recurrent disc herniation, and frequency of reoperation for recurrent disc herniation was recorded from each study.

\section{Literature Search}

The literature search yielded 1172 published studies. After reviewing the titles of these 1172 studies, 327 abstracts were identified that involved lumbar discectomy for 
primary lumbar disc herniation and were reviewed. This identified 179 studies reporting more than 6-month outcomes of at least one discectomy cohort. The articles of these 179 studies were reviewed in their entirety. After excluding studies that did not report the percentage of patients with persistent back or leg pain more than 6 months after discectomy or did not report the rate of same-level recurrent herniation, 90 studies were included for analysis. A total of 21,180 patients were available for analysis in this study.

\section{Prospective Study}

\section{Patient Selection}

All patients undergoing discectomy for a lumbar herniated disc were enrolled into our institution's prospective spinal outcomes registry over a 3-year period (2010-2013). All patients had (1) radicular leg pain; (2) intervertebral disc herniation seen on MRI corresponding to radicular level; (3) age 18 to 70 years; and (4) failure of at least 6 weeks of medical management, which included physical therapy, epidural injections, antiinflammatory medications, and opioid analgesics. Patients were excluded if they had an extraspinal cause of back/neck pain or radiculopathy, an active medical or workmen's compensation lawsuit, or were unwilling or unable to participate with followup procedures. Only patients with 1 year or more of clinical outcomes postoperatively were included in the study. During the study period (October 2010 to March 2013), a total of 192 patients underwent discectomy for lumbar disc herniation and radicular leg pain at our institution. One hundred fifteen patients were more than 12 months from surgery, and 103 (90\%) of them were available for 1-year outcomes assessment. Of these 115 patients, nine were lost to followup (7.8\%) and three (2.6\%) did not meet our inclusion criteria for the study. Thirty-five patients had passed 24 months from surgery, $30(85 \%)$ of whom were available for 2-year outcomes assessment.

\section{Clinical Outcomes Measures}

Patient demographics, disease characteristics, treatment variables, readmissions/reoperations, and all 90-day surgical morbidity were assessed prospectively for each case and entered into a web-based portal (REDCap). Baseline, 3-month, 1-year, and 2-year postoperative pain, disability, and quality of life were prospectively accessed by phone interview by an independent technician (SKM) not involved with clinical care. Patient-reported outcome instruments (PROi) included the Numeric Rating Scale
(NRS) for low back pain and leg pain [30, 35], Oswestry Disability Index (ODI) [25], ED-5D [24], SF-12 physical component summary (PCS), and SF-12 mental component summary (MCS) [90].

\section{Measure of Recurrent Back Pain and Disability}

Patients were considered to have achieved treatment response after surgery at 3-months followup. Patients with 1year and 2-years followup were examined to identify those who had subsequent deterioration as compared with their 3-month levels. The threshold of deterioration used to classify recurrent or delayed onset of new low back dysfunction was the minimum clinically important difference (MCID) values for ODI, NRS-back pain, and NRS-leg pain as described by Solberg et al. [80]. Cutoff values for a clinically meaningful decline in patient health and back/leg pain were change scores between the 3-month postoperative score and the 1-year or 2-year score of at least $20 \%$ (ODI) and 2.5 (NRS back) and 3.5 (NRS leg on a scale of $0-10)$ [80]. Any patient with a change score from 3-month to 1-year followup or from 3-month to 2-year followup that represented a decline greater than MCID thresholds in any one of these outcomes measures was considered to have developed postdiscectomy onset of low back pain and dysfunction.

\section{Statistical Analysis}

Parametric data were given as mean $\pm \mathrm{SD}$ and compared by Student's t-test. Nonparametric data were given as median (interquartile range) and compared by MannWhitney U-test. Nominal data were compared with the chi square test. Probability values $<0.05$ were considered statistically significant.

\section{Results}

Systematic Review

Short-term and Long-term Outcomes (recurrent back/leg pain)

Short-term outcome (6-24 months) after discectomy was reported in 39 discectomy cohorts $(\mathrm{n}=8156)$. Among the included studies, the proportion of patients reporting recurrent back or leg pain ranged from $3 \%$ to $34 \%$ (Table 1).

Long-term outcome (> 24 months) after discectomy was reported in 28 discectomy cohorts $(\mathrm{n}=6255)$. Among the included studies, the proportion of patients reporting 


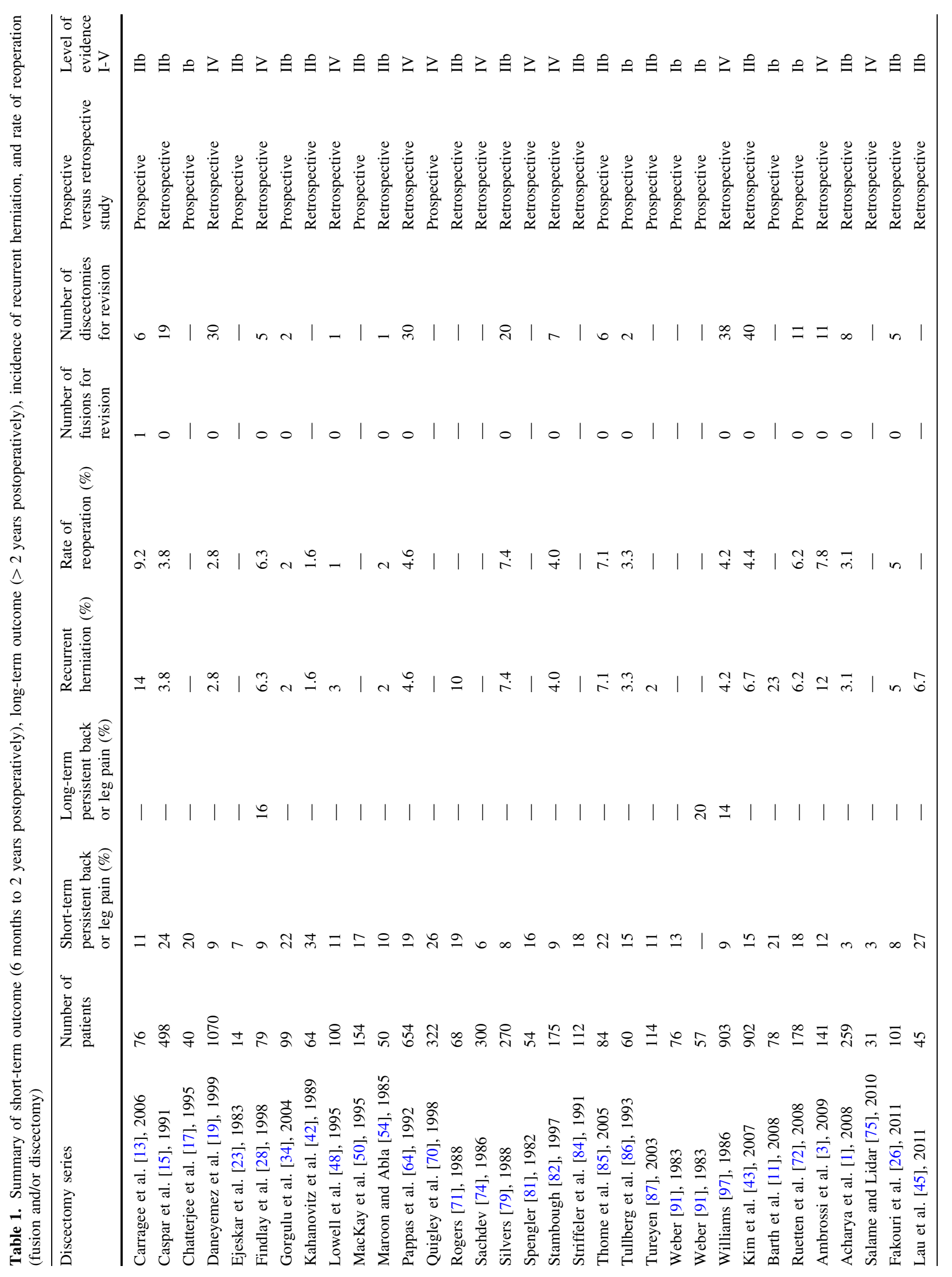




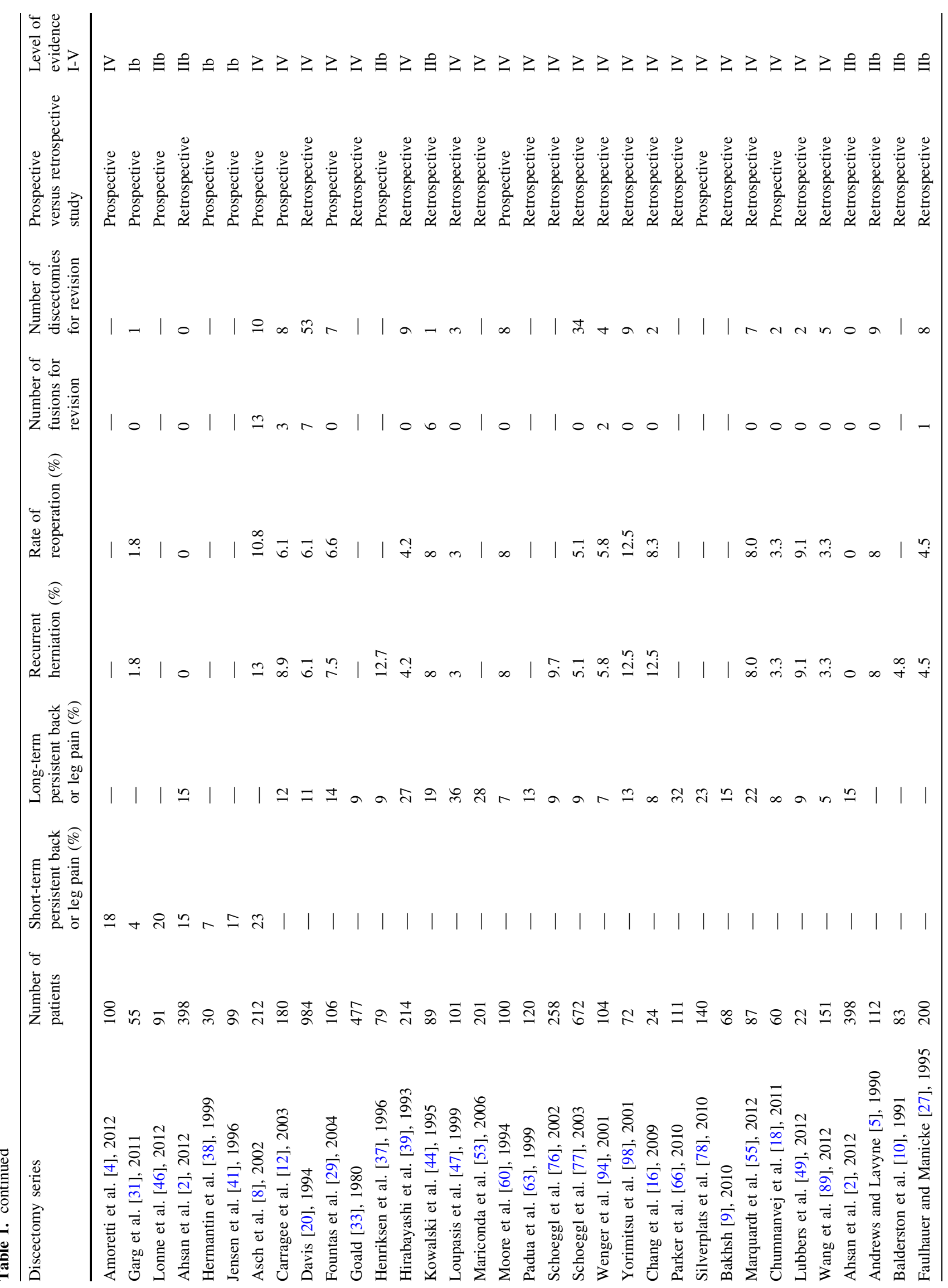




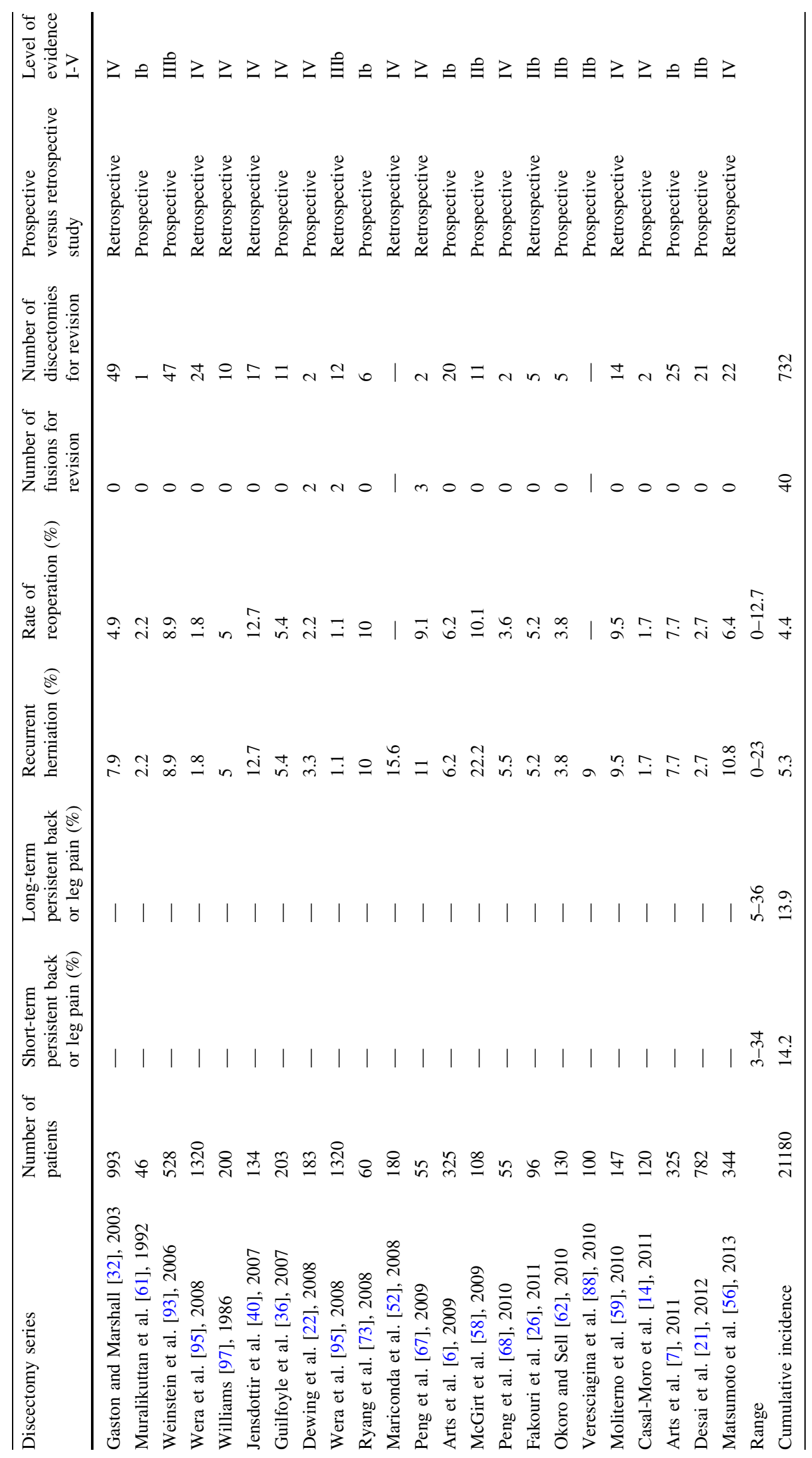


recurrent back or leg pain ranged from $5 \%$ to $36 \%$ (Table 1). Levels of evidence on the endpoint of short- and long-term low-back pain ranged from Ib to IV (Table 1).

\section{Recurrent Disc Herniation and Reoperation}

The incidence of recurrent disc herniation was reported in 70 studies $(n=18,085)$. Among the included studies, the incidence of same-level recurrent disc herniation ranged from $0 \%$ to $23 \%$ with 61 studies reporting a reoperation rate (Table 1). The revision procedure was fusion in $5 \%$ and revision discectomy in $95 \%$ of the cases. Levels of evidence on the endpoint of recurrent herniation and reoperation ranged from Ib to IV (Table 1).

\section{Prospective Cohort Study}

\section{Surgical Treatment and Complications}

The baseline characteristics of prospective cohort are described (Table 2). The mean length of surgery was $90.42 \pm 34.18$ minutes with an average blood loss of $86.17 \pm 117.13 \mathrm{~mL}$ and a median (interquartile range) hospital stay of 1 (1-2) day. Postoperative complications occurred in a total of seven (7\%) patients and included wound hematoma, wound infection, cerebrospinal fluid leak, deep venous thrombosis, and new neurologic deficit (Table 3).

\section{Postoperative Recurrent Low Back Pain and Influence on Patient-reported Outcomes}

At 3 months, none of the patients were found to have a clinically important (above the MCID) decline in low back disability (ODI) compared with baseline, but three (3\%) patients were found to have a clinically important (above the minimum clinically important difference) decline in low back pain (NRS) (Table 4).

At 1-year followup, there were 23 (22\%) patients who reported clinically important (above the MCID) worsening of low back pain (NRS) or disability (ODI) compared with 3 -month levels. The mean change scores from 3 to 12 months for worsening ODI (\%), NRS-back, and NRSleg were $10.70 \pm 14.47,2.65 \pm 2.72$, and $3.08 \pm 3.42$, respectively (Table 5). At 2-year followup, there were eight $(26 \%)$ patients who reported clinically important (MCID) worsening of low back pain (NRS) or disability (ODI) compared with 3-month levels. The mean change scores from 3 to 24 months for worsening ODI (\%), NRS-
Table 2. Baseline characteristics of the prospective cohort with 12-month followup

\begin{tabular}{ll}
\hline Variable & Number $(\%)$ \\
\hline Number & 103 \\
Mean age (years)* & $42.9 \pm 13.1$ \\
Male sex (\%) & $52(50)$ \\
Motor deficit (\%) & $48(47)$ \\
Mean number of levels* & $1.08 \pm 0.28$ \\
Current smoker (\%) & $46(45)$ \\
CAD (\%) & $6(6)$ \\
HTN $(\%)$ & $29(28)$ \\
MI $(\%)$ & $0(0)$ \\
AFIB $(\%)$ & $1(1)$ \\
CHF (\%) & $2(2)$ \\
COPD (\%) & $0(0)$ \\
Arthritis $(\%)$ & $35(34)$ \\
Diabetes $(\%)$ & $17(17)$ \\
Osteoporosis $(\%)$ & $0(0)$ \\
BMI (kg/m $\left.{ }^{2}\right)^{*}$ & $29.0 \pm 6.8$ \\
EQ-5D score* & $0.49 \pm 0.23$ \\
SF-12 PCS* & $28.73 \pm 9.10$ \\
SF-12 MCS* & $44.34 \pm 12.20$ \\
ODI score (\%)* & $52.16 \pm 18.42$ \\
NRS-back score* & $5.56 \pm 3.39$ \\
NRS-leg score* & $7.49 \pm 2.35$ \\
\hline &
\end{tabular}

* Values are mean $\pm \mathrm{SD} ; \mathrm{CAD}=$ coronary artery disease; $\mathrm{HTN}=$ hypertension; $\mathrm{MI}=$ myocardial infarction; $\mathrm{AFIB}=$ atrial fibrillation; $\mathrm{CHF}=$ congestive heart failure; $\mathrm{COPD}=$ chronic obstructive pulmonary disease; $\mathrm{BMI}=$ body mass index; PCS = physical component summary; MCS = mental component summary; ODI = Oswestry Disability Index; NRS = Numeric Rating Scale.

back, and NRS-leg were $12.70,4.05$, and 2.78 , respectively (Table 5).

Recurrence of back and leg pain at 1- and 2-year followup led to worse PROs (Fig. 1). As compared with the patients who showed improvement at 1 year $(\mathrm{n}=80)$ versus those who declined at 1 year $(n=23)$, these patients with recurrent back pain reported higher disability (ODI) (13.5 versus 31.9, $\mathrm{p}<0.001)$, and poorer quality of life (EQ-5D) (0.86 versus 0.74, $\mathrm{p}=0.003$ ) and general health state SF-12 PCS (48.1 versus 38.1, $\mathrm{p}=0.002$ ) and SF-12 MCS (53.1 versus 48.8, $\mathrm{p}=0.08$ ).

\section{Discussion}

Long-term postdiscectomy degenerative disc disease and low back pain is a well-recognized disorder; however, its patient-centered characterization and quantification are 
lacking. We performed a systematic literature review and prospective longitudinal study to determine the incidence of recurrent degenerative back pain and quantify its effect on patients' pain, disability, and quality of life.

The limitations inherent in this study have implications for its interpretation. First, there was a high degree of variation in surgical techniques used to perform lumbar discectomy in the literature review. The values deduced from our systematic review only apply for discectomy as a

Table 3. Operative characteristics of the prospective cohort

\begin{tabular}{ll}
\hline Approach & Number $(\%)$ \\
\hline Open microdiscectomy & $11(11)$ \\
Tubular microdiscectomy & $92(89)$ \\
Operative time (minutes)* & $90.42 \pm 34.18$ \\
Blood loss (mL)* & $86.17 \pm 117.13$ \\
Length of hospital stay (days) & 1 (range, 1-2) \\
Intraoperative complications, number (\%) & \\
Dural tear & $1(1)$ \\
Nerve root injury & 0 \\
Postoperative complications & \\
Wound hematoma & $1(1)$ \\
Wound infection & $3(3)$ \\
Cerebrospinal fluid leak & $2(2)$ \\
Deep venous thrombosis & 0 \\
New neurological deficit & $1(1)$ \\
Recurrent disk herniation (same level) & $9(9)$ \\
Disk herniation other level & $1(1)$ \\
Return to operating room within 90 days & \\
Wound infection & $1(1)$ \\
Stenosis & $0(0)$ \\
Dural tear & $0(0)$ \\
Cerebrospinal fluid leak & $2(2)$ \\
Cauda equina syndrome & $0(0)$ \\
\hline
\end{tabular}

* Values are mean $\pm \mathrm{SD}$. broad entity and are not necessarily reflective of a specific discectomy technique. Additionally, the level of evidence of studies in the systematic review ranged from Ib to IV. This introduces selection bias, transfer bias, and assessment bias and the estimation of frequency of low back pain is likely to be a low-end estimate. Lastly, our study has no patients with long-term followup ( $>2$ years) and therefore comparison with the long-term estimate of persistent back/ leg pain incidence found in the literature review could not be performed. Another study with a larger sample size and more patients with long-term followup is necessary to further corroborate the results found in our literature review.

In a systematic literature review, we found that the shortterm and long-term proportion of recurrent back pain after primary single-level lumbar discectomy ranged from $3 \%$ to $34 \%$ and $5 \%$ to $36 \%$, respectively. The incidence of recurrent disc herniation was $5.3 \%$. Our prospective, longitudinal PRO study validated these literature review findings, suggesting that when applying an MCID threshold of clinically significant deterioration with validated outcome instruments, as many as one in four patients undergoing discectomy may experience a clinically meaningful recurrence of low back pain and dysfunction. Although as many as $25 \%$ of patient in our series experienced worsening back pain and disability by 2 years, their level of low back pain and dysfunction remained better than that experienced at the time of the index disc herniation procedure. Furthermore, none of these patients underwent a fusion procedure or operative intervention for these symptoms at 2 years, although it is possible they may come to attention for these symptoms over the longer term. Schoeggl et al. [76] demonstrated that $24 \%$ of patients experienced persistent or recurrent pain at a mean followup of 7.3 years. Carragee et al. [13] reported an $11 \%$ incidence of persistent back or leg pain after limited discectomy and a $23 \%$ incidence of persistent back or leg pain after aggressive discectomy. As such, at least some of the variability observed in the literature may be secondary to varying surgical technique.

Table 4. Summary of clinical outcomes data for all patients included in the study*

\begin{tabular}{lcccc}
\hline Variable & Preoperative $(\mathrm{n}=103)$ & 3 months $(\mathrm{n}=103)$ & 1 year $(\mathrm{n}=103)$ & 2 years $(\mathrm{n}=30)$ \\
\hline EQ-5D & $0.49 \pm 0.23$ & $0.81 \pm 0.23$ & $0.83 \pm 0.19$ & $0.84 \pm 0.14$ \\
SF-12 PCS & $28.73 \pm 9.10$ & $45.82 \pm 10.87$ & $45.82 \pm 12.03$ & $45.93 \pm 10.89$ \\
SF-12 MCS & $44.34 \pm 12.20$ & $53.16 \pm 8.99$ & $52.14 \pm 9.32$ & $55.06 \pm 9.22$ \\
ODI & $52.16 \pm 18.42$ & $17.30 \pm 17.26$ & $17.65 \pm 18.56$ & $19.33 \pm 20.42$ \\
NRS-back & $5.56 \pm 3.39$ & $2.22 \pm 2.51$ & $2.88 \pm 2.82$ & $2.90 \pm 3.12$ \\
NRS-leg & $7.49 \pm 2.35$ & $2.11 \pm 2.82$ & $2.51 \pm 3.14$ & $2.21 \pm 3.11$ \\
\hline
\end{tabular}

* Mean \pm SD for all variables at each assessment. Significant improvement from baseline was seen for all variables $(\mathrm{p}<0.01)$; PCS $=$ physical component summary; MCS = mental component summary; ODI = Oswestry Disability Index; NRS = Numeric Rating Scale. 
Table 5. Summary of outcomes reported for 23 of 103 (23\%) patients identified as having 1-year and eight of 30 (26\%) patients identified as having 2-year recurrent low back pain and disability after discectomy (defined by MCID thresholds)*

\begin{tabular}{lcccc}
\hline Variable & Preoperative $(\mathrm{n}=23)$ & 3 months $(\mathrm{n}=23)$ & 1 year $(\mathrm{n}=23)$ & 2 years $(\mathrm{n}=8)$ \\
\hline EQ-5D & $0.42 \pm 0.25$ & $0.82 \pm 0.14$ & $0.74 \pm 0.16$ & $0.75 \pm 0.08$ \\
SF-12 PCS & $28.25 \pm 7.42$ & $43.99 \pm 11.31$ & $38.12 \pm 13.39$ & $36.67 \pm 8.74$ \\
SF-12 MCS & $40.89 \pm 13.89$ & $53.17 \pm 10.53$ & $48.76 \pm 10.58$ & $53.30 \pm 10.75$ \\
ODI & $59.30 \pm 18.43$ & $21.22 \pm 18.45$ & $31.91 \pm 18.27$ & $33.75 \pm 15.69$ \\
NRS-back & $7.00 \pm 2.78$ & $2.70 \pm 2.88$ & $5.35 \pm 2.53$ & $6.75 \pm 1.28$ \\
NRS-leg & $8.09 \pm 1.62$ & $2.22 \pm 2.78$ & $5.30 \pm 3.14$ & $5.00 \pm 3.46$ \\
\hline
\end{tabular}

Values are mean $\pm \mathrm{SD}$; *despite a delayed decline in these patients, back pain, disability, and quality of life remained improved versus preoperative levels $(\mathrm{p}<0.05)$; PCS = physical component summary; MCS = mental component summary; ODI = Oswestry Disability Index; NRS = Numeric Rating Scale; MCID = minimum clinically important difference.

Numeric Rating Scale-Back pain

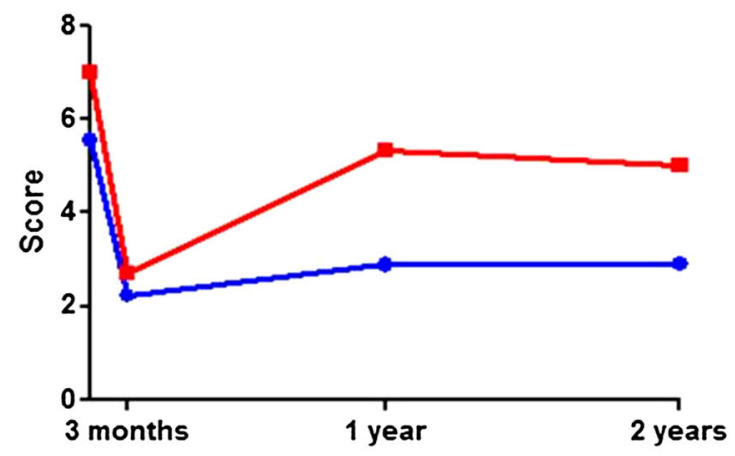

SF-12 PCS

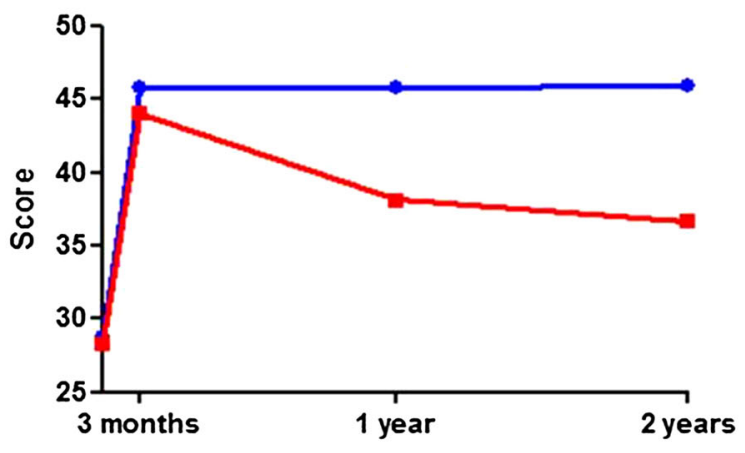

Numeric Rating Scale-Leg pain

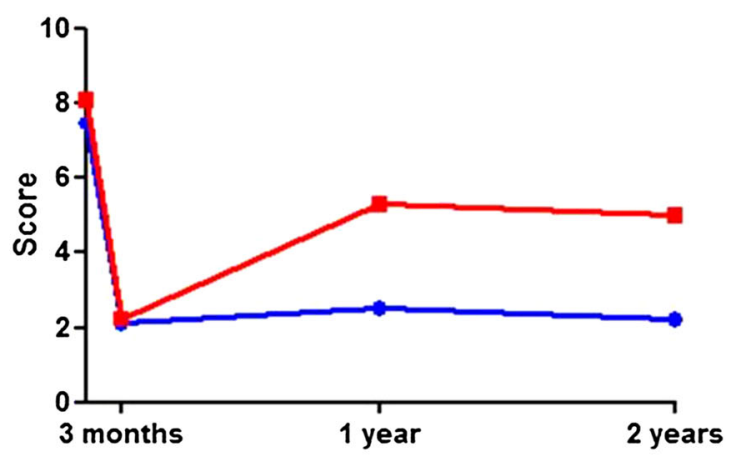

ODI

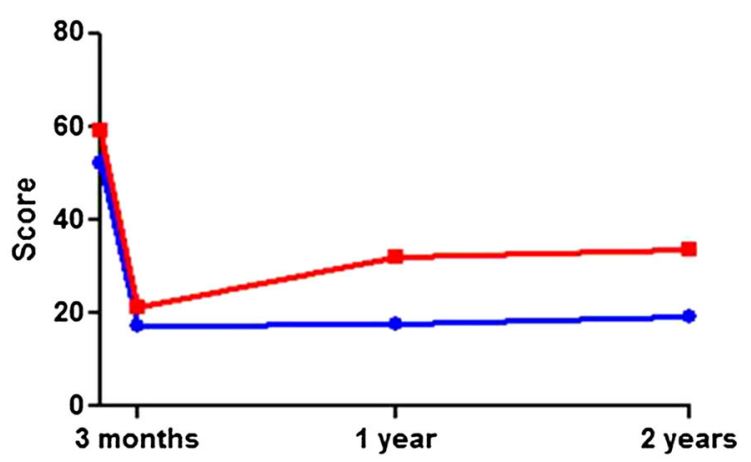

All patients

\section{Patients with recurrent back pain}

Fig. 1 PROs at baseline, 3 months, 1 year, and 2 years are shown. The blue line represents the complete cohort, whereas the red line represents the patients who showed recurrence of symptoms and decline at 1-year and 2-year followup.

In our prospective study, we found that $9 \%$ of patients had radiographic same-level recurrent lumbar disc herniation and 6\% were symptomatic enough to undergo a reoperation. The values found in our prospective registry for the frequency of same-level recurrent herniation and reoperation fall neatly within the range from $0 \%$ to $23 \%$ found in our literature review. Although the incidence of recurrent disc herniation is less than that of delayed postoperative back pain, its severity is much greater, and patients required reoperation in the majority of cases. Our study demonstrated that recurrence of back and leg pain at 1- and 2-year followup led to worse patient-reported 
outcomes at those followup points. Although not a surprising finding, this is the first study to demonstrate that recurrent/persistent back pain after lumbar discectomy results in an associated decline in functional status as measured by validated outcome metrics for disability (ODI), health utility (EQ-5D), and general quality of life (SF-12).

In an analysis of a systematic literature review and prospective longitudinal outcomes study, the proportion of 2-year, same-level disc herniation requiring revision discectomy was nearly $6 \%$ in both analyses. Two-year recurrent low back pain after discectomy may occur in $15 \%$ to $25 \%$ of patients depending on the level of recurrent pain considered clinically significant. Although delayed recurrent back pain exceeding MCID occurs not infrequently, the level of pain and disability remains less than that experienced at the time of prior disc herniation and index surgery. Despite this, recurrent back pain leads to worse PROs including higher disability and poorer general health state (SF-12 PCS and SF-12 MCS) and quality of life (EQ5D) as demonstrated by the results of our study. Five- and 10-year followup studies are needed to further characterize the frequency and severity of postdiscectomy degenerative low back pain because this can affect long-term PROs as a result of higher preoperative expectations and lead to poor postoperative satisfaction.

\section{References}

1. Acharya KN, Nathan TS, Kumar JR, Menon KV. Primary and revision lumbar discectomy: a three-year review from one center. Indian J Orthop. 2008;42:178-181.

2. Ahsan K, Najmus S, Hossain A, Khan SI, Awwal MA. Discectomy for primary and recurrent prolapse of lumbar intervertebral discs. J Orthop Surg (Hong Kong). 2012;20:7-10.

3. Ambrossi GL, McGirt MJ, Sciubba DM, Witham TF, Wolinsky JP, Gokaslan ZL, Long DM. Recurrent lumbar disc herniation after single-level lumbar discectomy: incidence and health care cost analysis. Neurosurgery. 2009;65:574-578; discussion 578.

4. Amoretti N, Hauger O, Marcy PY, Amoretti ME, Lesbats V, Yvonne M, Ianessi A, Boileau P. Percutaneous discectomy on lumbar radiculopathy related to disk herniation: why under CT guidance? An open study of 100 consecutive patients. Eur J Radiol. 2012;81:1259-1264.

5. Andrews DW, Lavyne MH. Retrospective analysis of microsurgical and standard lumbar discectomy. Spine (Phila Pa 1976). 1990;15:329-335.

6. Arts MP, Brand R, van den Akker ME, Koes BW, Bartels RH, Peul WC. Tubular diskectomy vs conventional microdiskectomy for sciatica: a randomized controlled trial. JAMA. 2009;302:149-158.

7. Arts MP, Brand R, van den Akker ME, Koes BW, Bartels RH, Tan WF, Peul WC. Tubular diskectomy vs conventional microdiskectomy for the treatment of lumbar disk herniation: 2-year results of a double-blind randomized controlled trial. Neurosurgery. 2011;69:135-144; discussion 144.
8. Asch HL, Lewis PJ, Moreland DB, Egnatchik JG, Yu YJ, Clabeaux DE, Hyland AH. Prospective multiple outcomes study of outpatient lumbar microdiscectomy: should 75 to $80 \%$ success rates be the norm? J Neurosurg. 2002;96(Suppl):34-44.

9. Bakhsh A. Long-term outcome of lumbar disc surgery: an experience from Pakistan. J Neurosurg Spine. 2010;12:666-670.

10. Balderston RA, Gilyard GG, Jones AA, Wiesel SW, Spengler DM, Bigos SJ, Rothman RH. The treatment of lumbar disc herniation: simple fragment excision versus disc space curettage. $J$ Spinal Disord. 1991;4:22-25.

11. Barth M, Weiss C, Thome C. Two-year outcome after lumbar microdiscectomy versus microscopic sequestrectomy: part 1: evaluation of clinical outcome. Spine (Phila Pa 1976). 2008;33:265-272.

12. Carragee EJ, Han MY, Suen PW, Kim D. Clinical outcomes after lumbar discectomy for sciatica: the effects of fragment type and anular competence. J Bone Joint Surg Am. 2003;85:102-108.

13. Carragee EJ, Spinnickie AO, Alamin TF, Paragioudakis S. A prospective controlled study of limited versus subtotal posterior discectomy: short-term outcomes in patients with herniated lumbar intervertebral discs and large posterior anular defect. Spine (Phila Pa 1976). 2006;31:653-657.

14. Casal-Moro R, Castro-Menendez M, Hernandez-Blanco M, Bravo-Ricoy JA, Jorge-Barreiro FJ. Long-term outcome after microendoscopic diskectomy for lumbar disk herniation: a prospective clinical study with a 5-year follow-up. Neurosurgery. 2011;68:1568-1575; discussion 1575.

15. Caspar W, Campbell B, Barbier DD, Kretschmmer R, Gotfried Y. The Caspar microsurgical discectomy and comparison with a conventional standard lumbar disc procedure. Neurosurgery. 1991;28:78-86; discussion 86-87.

16. Chang SS, Fu TS, Liang YC, Lia PL, Niu CC, Chen LH, Chen WJ. Results of microendoscopic discectomy performed in the 26 cases with a minimum 3 years follow-up. Chang Gung Med J. 2009;32:89-97.

17. Chatterjee S, Foy PM, Findlay GF. Report of a controlled clinical trial comparing automated percutaneous lumbar discectomy and microdiscectomy in the treatment of contained lumbar disc herniation. Spine (Phila Pa 1976). 1995;20:734-738.

18. Chumnanvej S, Kesornsak W, Sarnvivad P, Paiboonsirijit S, Kuansongthum V. Full endoscopic lumbar discectomy via interlaminar approach: 2-year results in Ramathibodi Hospital. J Med Assoc Thai. 2011;94:1465-1470.

19. Daneyemez M, Sali A, Kahraman S, Beduk A, Seber N. Outcome analyses in 1072 surgically treated lumbar disc herniations. Minim Invasive Neurosurg. 1999;42:63-68.

20. Davis RA. A long-term outcome analysis of 984 surgically treated herniated lumbar discs. J Neurosurg. 1994;80:415-421.

21. Desai A, Bekelis K, Ball PA, Lurie J, Mirza SK, Tosteson TD, Zhao W, Weinstein JN. Spine patient outcomes research trial: do outcomes vary across centers for surgery for lumbar disc herniation? Neurosurgery. 2012;71:833-842.

22. Dewing CB, Provencher MT, Riffenburgh RH, Kerr S, Manos RE. The outcomes of lumbar microdiscectomy in a young, active population: correlation by herniation type and level. Spine (Phila Pa 1976). 2008;33:33-38.

23. Ejeskar A, Nachemson A, Herberts P, Lysell E, Andersson G, Irstam L, Peterson LE. Surgery versus chemonucleolysis for herniated lumbar discs. A prospective study with random assignment. Clin Orthop Relat Res. 1983;174:236-242.

24. EuroQol, EuroQol—a new facility for the measurement of healthrelated quality of life. The EuroQol Group. Health Policy. 1990;16:199-208.

25. Fairbank JC, Pynsent PB. The Oswestry Disability Index. Spine (Phila Pa 1976). 2000;25:2940-2952; discussion 2952. 
26. Fakouri B, Patel V, Bayley E, Srinivas S. Lumbar microdiscectomy versus sequesterectomy/free fragmentectomy: a long-term (>2 y) retrospective study of the clinical outcome. J Spinal Disord Tech. 2011;24:6-10.

27. Faulhauer K, Manicke C. Fragment excision versus conventional disc removal in the microsurgical treatment of herniated lumbar disc. Acta Neurochir (Wien). 1995;133:107-111.

28. Findlay GF, Hall BI, Musa BS, Oliveira MD, Fear SC. A 10-year follow-up of the outcome of lumbar microdiscectomy. Spine (Phila Pa 1976). 1998;23:1168-1171.

29. Fountas KN, Kapsalaki EZ, Feltes CH, Smisson HF 3rd, Johnston KW, Vogel RL, Robinson JS Jr. Correlation of the amount of disc removed in a lumbar microdiscectomy with long-term outcome. Spine (Phila Pa 1976). 2004;29:2521-2524; discussion 2525-2526.

30. Gallagher EJ, Liebman M, Bijur PE. Prospective validation of clinically important changes in pain severity measured on a visual analog scale. Ann Emerg Med. 2001;38:633-638.

31. Garg B, Nagraja UB, Jayaswal A. Microendoscopic versus open discectomy for lumbar disc herniation: a prospective randomised study. J Orthop Surg (Hong Kong). 2011;19:30-34.

32. Gaston P, Marshall RW. Survival analysis is a better estimate of recurrent disc herniation. J Bone Joint Surg Br. 2003;85:535-537.

33. Goald HJ. Microlumbar discectomy: follow-up of 477 patients. $J$ Microsurg. 1980;2:95-100.

34. Gorgulu A, Simsek O, Cobanoglu S, Imer M, Parsak T. The effect of epidural free fat graft on the outcome of lumbar disc surgery. Neurosurg Rev. 2004;27:181-184.

35. Gronblad M, Hupli M, Wennerstrand P, Jarvinen E, Lukinmaa A, Kouri JP, Karaharju EO. Intercorrelation and test-retest reliability of the Pain Disability Index (PDI) and the Oswestry Disability Questionnaire (ODQ) and their correlation with pain intensity in low back pain patients. Clin J Pain. 1993;9:189-195.

36. Guilfoyle MR, Ganesan D, Seeley H, Laing RJ. Prospective study of outcomes in lumbar discectomy. Br J Neurosurg. 2007;21:389-395.

37. Henriksen L, Schmidt K, Eskesen V, Jantzen E. A controlled study of microsurgical versus standard lumbar discectomy. $\mathrm{Br} \mathrm{J}$ Neurosurg. 1996;10:289-293.

38. Hermantin FU, Peters T, Quartararo L, Kambin P. A prospective, randomized study comparing the results of open discectomy with those of video-assisted arthroscopic microdiscectomy. $J$ Bone Joint Surg Am. 1999;81:958-965.

39. Hirabayashi S, Kumano K, Ogawa Y, Aota Y, Maehiro S. Microdiscectomy and second operation for lumbar disc herniation. Spine (Phila Pa 1976). 1993;18:2206-2211.

40. Jensdottir M, Gudmundsson K, Hannesson B, Gudmundsson G. 20 years follow-up after the first microsurgical lumbar discectomies in Iceland. Acta Neurochir (Wien). 2007;149:51-58; discussion $57-58$.

41. Jensen TT, Asmussen K, Berg-Hansen EM, Lauritsen B, Manniche C, Vinterberg H, Jensen L, Kramhoft J. First-time operation for lumbar disc herniation with or without free fat transplantation. Prospective triple-blind randomized study with reference to clinical factors and enhanced computed tomographic scan 1 year after operation. Spine (Phila Pa 1976). 1996;21:1072-1076.

42. Kahanovitz N, Viola K, Muculloch J. Limited surgical discectomy and microdiscectomy. A clinical comparison. Spine (Phila Pa 1976). 1989;14:79-81.

43. Kim MJ, Lee SH, Jung ES, Son BG, Choi ES, Shin JH, Sung JK, Chi YC. Targeted percutaneous transforaminal endoscopic diskectomy in 295 patients: comparison with results of microscopic diskectomy. Surg Neurol. 2007;68:623-631.

44. Kowalski JM, Olsewski JM, Simmons ED Jr. Results of intervertebral diskectomy without fusion at L4-5 versus L5-S1. $J$ Spinal Disord. 1995;8:457-463.
45. Lau D, Han SJ, Lee JG, Lu DC, Chou D. Minimally invasive compared to open microdiscectomy for lumbar disc herniation. $J$ Clin Neurosci. 2011;18:81-84.

46. Lonne G, Solberg TK, Sjaavik K, Nygaard OP. Recovery of muscle strength after microdiscectomy for lumbar disc herniation: a prospective cohort study with 1-year follow-up. Eur Spine J. 2012;21:655-659.

47. Loupasis GA, Stamos K, Katonis PG, Sapkas G, Korres DS, Hartofilakidis G. Seven- to 20-year outcome of lumbar discectomy. Spine (Phila Pa 1976). 1999;24:2313-2317.

48. Lowell TD, Errico TJ, Fehlings MG, DiBartolo TJ, Ladosi L. Microdiskectomy for lumbar disk herniation: a review of 100 cases. Orthopedics. 1995;18:985-990.

49. Lubbers T, Abuamona R, Elsharkawy AE. Percutaneous endoscopic treatment of foraminal and extraforaminal disc herniation at the L5-S1 level. Acta Neurochir (Wien). 2012;154:1789-1795.

50. MacKay MA, Fischgrund JS, Herkowitz HN, Kurz LT, Hecht B, Schwartz M. The effect of interposition membrane on the outcome of lumbar laminectomy and discectomy. Spine (Phila Pa 1976). 1995;20:1793-1796.

51. Macnab I. Negative disc exploration. An analysis of the causes of nerve-root involvement in sixty-eight patients. J Bone Joint Surg Am. 1971;53:891-903.

52. Mariconda M, Galasso O, Secondulfo V, Cozzolino A, Milano C. The functional relevance of neurological recovery after lumbar discectomy: a follow-up of more than 20 years. J Bone Joint Surg Br. 2008;90:622-628.

53. Mariconda M, Galasso O, Secondulfo V, Rotonda GD, Milano C. Minimum 25-year outcome and functional assessment of lumbar discectomy. Spine (Phila Pa 1976). 2006;31:2593-2599; discussion 2600-2601.

54. Maroon JC, Abla A. Microdiscectomy versus chemonucleolysis. Neurosurgery. 1985;16:644-649.

55. Marquardt G, Bruder M, Theuss S, Setzer M, Seifert V. Ultra-longterm outcome of surgically treated far-lateral, extraforaminal lumbar disc herniations: a single-center series. Eur Spine J. 2012;21:660-665.

56. Matsumoto $\mathrm{M}$, Watanabe $\mathrm{K}$, Hosogane $\mathrm{N}$, Tsuji $\mathrm{T}$, Ishii $\mathrm{K}$, Nakamura M, Chiba K, Toyama Y. Recurrence of lumbar disc herniation after microendoscopic discectomy. J Neurol Surg A Cent Eur Neurosurg. 2013;74:222-227.

57. McGirt MJ, Ambrossi GL, Datoo G, Sciubba DM, Witham TF, Wolinsky JP, Gokaslan ZL, Bydon A. Recurrent disc herniation and long-term back pain after primary lumbar discectomy: review of outcomes reported for limited versus aggressive disc removal. Neurosurgery. 2009;64:338-344; discussion 344-345.

58. McGirt MJ, Eustacchio S, Varga P, Vilendecic M, Trummer M, Gorensek M, Ledic D, Carragee EJ. A prospective cohort study of close interval computed tomography and magnetic resonance imaging after primary lumbar discectomy: factors associated with recurrent disc herniation and disc height loss. Spine (Phila Pa 1976). 2009;34:2044-2051.

59. Moliterno JA, Knopman J, Parikh K, Cohan JN, Huang QD, Aaker GD, Grivoyannis AD, Patel AR, Hartl R, Boockvar JA. Results and risk factors for recurrence following single-level tubular lumbar microdiscectomy. J Neurosurg Spine. 2010;12:680-686.

60. Moore AJ, Chilton JD, Uttley D. Long-term results of microlumbar discectomy. Br J Neurosurg. 1994;8:319-326.

61. Muralikuttan KP, Hamilton A, Kernohan WG, Mollan RA, Adair IV. A prospective randomized trial of chemonucleolysis and conventional disc surgery in single level lumbar disc herniation. Spine (Phila Pa 1976). 1992;17:381-387.

62. Okoro T, Sell P. A short report comparing outcomes between L4/ L5 and L5/S1 single-level discectomy surgery. J Spinal Disord Tech. 2010;23:40-42. 
63. Padua R, Padua S, Romanini E, Padua L, de Santis E. Ten- to 15year outcome of surgery for lumbar disc herniation: radiographic instability and clinical findings. Eur Spine J. 1999;8:70-74.

64. Pappas CT, Harrington T, Sonntag VK. Outcome analysis in 654 surgically treated lumbar disc herniations. Neurosurgery. 1992;30:862-866.

65. Parker SL, Grahovac G, Vukas D, Ledic D, Vilendecic M, McGirt MJ. Cost savings associated with prevention of recurrent lumbar disc herniation with a novel annular closure device: a multicenter prospective cohort study. J Neurol Surg A Cent Eur Neurosurg. 2013;74:285-289.

66. Parker SL, Xu R, McGirt MJ, Witham TF, Long DM, Bydon A. Long-term back pain after a single-level discectomy for radiculopathy: incidence and health care cost analysis. J Neurosurg Spine. 2010;12:178-182.

67. Peng CW, Yeo W, Tan SB. Percutaneous endoscopic lumbar discectomy: clinical and quality of life outcomes with a minimum 2 year follow-up. J Orthop Surg Res. 2009;4:20.

68. Peng CW, Yeo W, Tan SB. Percutaneous endoscopic discectomy: clinical results and how it affects the quality of life. $J$ Spinal Disord Tech. 2010;23:425-430.

69. Prolo DJ, Oklund SA, Butcher M. Toward uniformity in evaluating results of lumbar spine operations. A paradigm applied to posterior lumbar interbody fusions. Spine (Phila Pa 1976). 1986;11:601-606.

70. Quigley MR, Bost J, Maroon JC, Elrifai A, Panahandeh M. Outcome after microdiscectomy: results of a prospective single institutional study. Surg Neurol. 1998;49:263-267; discussion 267-268.

71. Rogers LA. Experience with limited versus extensive disc removal in patients undergoing microsurgical operations for ruptured lumbar discs. Neurosurgery. 1988;22:82-85.

72. Ruetten S, Komp M, Merk H, Godolias G. Full-endoscopic interlaminar and transforaminal lumbar discectomy versus conventional microsurgical technique: a prospective, randomized, controlled study. Spine (Phila Pa 1976). 2008;33:931-939.

73. Ryang YM, Oertel MF, Mayfrank L, Gilsbach JM, Rohde V. Standard open microdiscectomy versus minimal access trocar microdiscectomy: results of a prospective randomized study. Neurosurgery. 2008;62:174-181; discussion 181-182.

74. Sachdev VP. Microsurgical lumbar discectomy: a personal series of 300 patients with at least 1 year of follow-up. Microsurgery. 1986;7:55-62.

75. Salame K, Lidar Z. Minimally invasive approach to far lateral lumbar disc herniation: technique and clinical results. Acta Neurochir (Wien). 2010;152:663-668.

76. Schoeggl A, Maier H, Saringer W, Reddy M, Matula C. Outcome after chronic sciatica as the only reason for lumbar microdiscectomy. J Spinal Disord Tech. 2002;15:415-419.

77. Schoeggl A, Reddy M, Matula C. Functional and economic outcome following microdiscectomy for lumbar disc herniation in 672 patients. J Spinal Disord Tech. 2003;16:150-155.

78. Silverplats K, Lind B, Zoega B, Halldin K, Rutberg L, Gellerstedt $\mathrm{M}$, Brisby H. Clinical factors of importance for outcome after lumbar disc herniation surgery: long-term follow-up. Eur Spine J. 2010;19:1459-1467.

79. Silvers HR. Microsurgical versus standard lumbar discectomy. Neurosurgery. 1988;22:837-841.

80. Solberg T, Johnsen LG, Nygaard OP, Grotle M. Can we define success criteria for lumbar disc surgery? Estimates for a substantial amount of improvement in core outcome measures. Acta Orthop. 2013;84:196-201.
81. Spengler DM. Lumbar discectomy. Results with limited disc excision and selective foraminotomy. Spine (Phila Pa 1976). 1982;7:604-607.

82. Stambough JL. Lumbar disk herniation: an analysis of 175 surgically treated cases. J Spinal Disord. 1997;10:488-492.

83. Stauffer RN, Coventry MB. Anterior interbody lumbar spine fusion. Analysis of Mayo Clinic series. J Bone Joint Surg Am. 1972;54:756-768.

84. Striffeler H, Groger U, Reulen HJ. 'Standard' microsurgical lumbar discectomy vs 'conservative' microsurgical discectomy. A preliminary study. Acta Neurochir (Wien). 1991;112:62-64.

85. Thome C, Barth M, Scharf J, Schmiedek P. Outcome after lumbar sequestrectomy compared with microdiscectomy: a prospective randomized study. J Neurosurg Spine. 2005;2:271-278.

86. Tullberg T, Isacson J, Weidenhielm L. Does microscopic removal of lumbar disc herniation lead to better results than the standard procedure? Results of a one-year randomized study. Spine (Phila Pa 1976). 1993;18:24-27.

87. Tureyen K. One-level one-sided lumbar disc surgery with and without microscopic assistance: 1-year outcome in 114 consecutive patients. J Neurosurg. 2003;99(Suppl):247-250.

88. Veresciagina K, Spakauskas B, Ambrozaitis KV. Clinical outcomes of patients with lumbar disc herniation, selected for onelevel open-discectomy and microdiscectomy. Eur Spine J. 2010;19:1450-1458.

89. Wang M, Zhou Y, Wang J, Zhang Z, Li C. A 10-year follow-up study on long-term clinical outcomes of lumbar microendoscopic discectomy. $J$ Neurol Surg A Cent Eur Neurosurg. 2012;73:195-198.

90. Ware J Jr, Kosinski M, Keller SD. A 12-Item Short-Form Health Survey: construction of scales and preliminary tests of reliability and validity. Med Care. 1996;34:220-233.

91. Weber H. Lumbar disc herniation. A controlled, prospective study with ten years of observation. Spine (Phila Pa 1976). 1983;8:131-140.

92. Weinstein JN, Lurie JD, Olson PR, Bronner KK, Fisher ES. United States' trends and regional variations in lumbar spine surgery: 1992-2003. Spine (Phila Pa 1976). 2006;31:2707-2714.

93. Weinstein JN, Lurie JD, Tosteson TD, Skinner JS, Hanscom B, Tosteson AN, Herkowitz H, Fischgrund J, Cammisa FP, Albert T, Deyo RA. Surgical vs nonoperative treatment for lumbar disk herniation: the Spine Patient Outcomes Research Trial (SPORT) observational cohort. JAMA. 2006;296:2451-2459.

94. Wenger M, Mariani L, Kalbarczyk A, Groger U. Long-term outcome of 104 patients after lumbar sequestrectomy according to Williams. Neurosurgery. 2001;49:329-334; discussion 334-335.

95. Wera GD, Marcus RE, Ghanayem AJ, Bohlman HH. Failure within one year following subtotal lumbar discectomy. $J$ Bone Joint Surg Am. 2008;90:10-15.

96. Williams RW. Microlumbar discectomy: a conservative surgical approach to the virgin herniated lumbar disc. Spine (Phila Pa 1976). 1978;3:175-182.

97. Williams RW. Microlumbar discectomy. A 12-year statistical review. Spine (Phila Pa 1976). 1986;11:851-852.

98. Yorimitsu E, Chiba K, Toyama Y, Hirabayashi K. Long-term outcomes of standard discectomy for lumbar disc herniation: a follow-up study of more than 10 years. Spine (Phila Pa 1976). 2001;26:652-657. 